\title{
THE EFFECTS OF SHORT TERM THERMAL CURE THERAPY ON SCAR TISSUE AND GENERAL PHYSICAL PARAMETERS IN BURN PATIENTS
}

\author{
M Anthonissen ${ }^{1,2}, \mathrm{~K}$ Maertens ${ }^{3,4}, \mathrm{~T}$ Vanhullebusch ${ }^{1}, \mathrm{M}$ Van Brussel, MD ${ }^{5}$, JP Fauville, MD6, D Jacquemin, MD7, \\ $\mathrm{S}$ Jennes, $\mathrm{MD}^{8}$, C Lafaire, MD ${ }^{4,9}, \mathrm{~S}$ Monstrey, $\mathrm{PhD}, \mathrm{MD}^{10}$, E Van den Kerckhove, $\mathrm{PhD}^{1,2}$
}

\section{Rationale}

Thermal cure therapy, an aspect of balneotherapy, is widely known in rehabilitation programs for musculoskeletal and dermatological diseases, although far less after burn injuries. Our explorative study investigated the effects of thermal cure therapy on physical parameters and scars in burn patients.

\section{Methods}

Fourteen burn patients ( 10 men and 4 women) between 18 and 56 years of age (mean $36.2 \pm 10.7$ years) followed a thermal cure therapy during three weeks in a thermal cure station in Avène ${ }^{\circledR}$ (France).
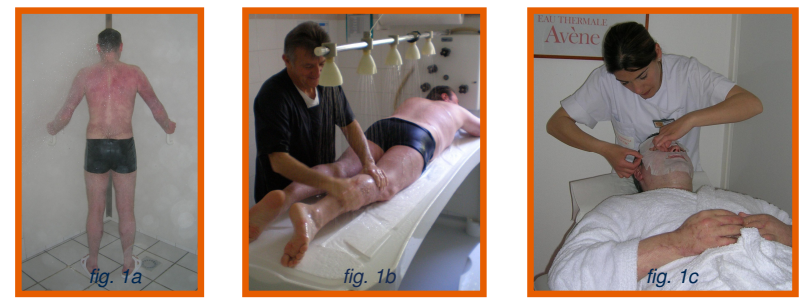

The thermal cure therapy consisted of standard baths, air bubble baths,

hydrojet-massaging baths, showers, sprays, filiform showers (fig. 1a), underwater massages (fig. 1b), localized pulverizations of face and hands, and thermal spring water compresses (fig. 1c).

Patients were recruited from different Belgian burn centers. Informed consent was obtained from all patients. General physical parameters like respiratory function, hand strength, physical fitness and joint motion were assessed. Scar related parameters were measured using objective instruments for sensory testing, color, transepidermal water loss, elasticity and using subjective questionnaires like POSAS (patient and observer scar assessment scale). All these parameters were obtained at baseline, during the intervention, and at follow-up two weeks and three months after the end of therapy. Friedman tests were used for detection of any significant change overall and paired Wilcoxon tests were used for the change observed three months after end of therapy compared to baseline.

\section{Acknowledgements}

This study was accomplished thanks to grants of the Belgian Burn Foundation and Avène ${ }^{\circledR}$.

\section{Results}

No significant relevant effects on general physical parameters were found. Objective measurements on scars showed no significant results, except a positive trend for erythema after three months $(p=0.05)$. All parameters of POSAS showed significant improvements after the three months evaluation period $(p \leq 0.002)$.
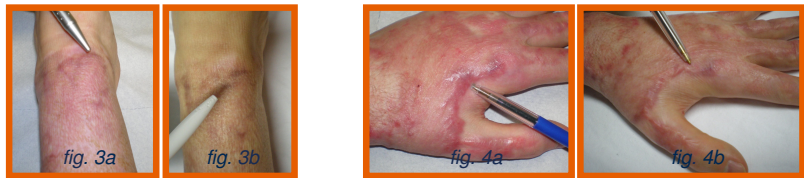

Evolution of scar on ankle-anterior (fig. 3a-b) and hand-dorsum (fig. 4a-b) before (a) and after (b) thermal cure therapy.

\section{Conclusion}

Thermal cure therapy showed a positive influence on scar perception of both burn patient and observer. Further research needs to be done to compare these results to patients following aquatic exercise or no additional therapy (control group).

\section{Literature}

- Young A. Rehabilitation of Burn Injuries. Phys Med Rehabil Clin N Am 2002;3:85-108.

- Johnson C. Pathologic manifestations of burn injury. In: Richard RL, Staley MJ. Burn care an rehabilitation principles and practice.

Philadelphia: F.A. Davis 1994;29-48.

- Esselman PC, Thomas BD, Magyar-Russel et al. Burn rehabilitation: State of the science. Am J Phys Med Rehabil 2006;85:383-413.

- Geytenbeek J, Evidence for effective hydrotherapy. Physiotherapy 2002;88514-529

- Van den Kerckhove $\mathrm{E}$ et al. The assessment of erythema and thickness on burn related scars during pressure garment therapy as a preventive measure for hypertrophic scarring. Burns. 2005 Sep;31(6):696-702.

- Van den Kerckhove $\mathrm{E}$ et al. Measurement of the transepidermal water loss rate and elasticity of burn scars with the Dermalab ${ }^{\circledR}$. Unpublished data.

- Draaijers LJ et al. The patient and observer scar assessment scale: a reliable and feasible tool for scar evaluation. Plast Reconstr Surg. 2004 Jun;113(7):1960-7

\footnotetext{
Katholieke Universiteit Leuven (KUL), Faculty of Kinesiology and Rehabilitation Sciences, Department of Rehabilitation Sciences, Tervuursevest 101, 3001 Heverlee, Belgium

University Hospital of Leuven campus Gasthuisberg, Department of Physical Medicine and Rehabilitation and Burn Center, Herestraat 49, 3000 Leuven, Belgium

3 Vrije Universiteit Brussel (VUB), Department of Clinical and Life Span Psychology, Pleinlaan 2, 3C235, 1050 Brussels, Belgium

4 Organisation for burns, scar after-care \& research (Oscare), Bredabaan 414a, 2170 Merksem, Belgium

5 University Hospital of Leuven campus Gasthuisberg, Department of Plastic and Reconstructive Surgery, Burn Center, Herestraat 49, 3000 Leuven, Belgium

6 IMTR Loverval, Burn Centre, rue de Villers 1, 6280 Loverval, Belgium

Centre Hospitalier Universitaire de Liège, Burn Center, Domaine Universitaire du Sart Tilman 35, 4000 Liège, Belgium

${ }^{8}$ Military Hospital Queen Astrid, Burn Centre Neder Over Heembeek, rue Bruyn 1, 1120 Brussels Belgium

9 University Hospital Antwerp Stuivenberg, Department of Plastic Surgery, Burn Center, Lange Beeldekensstraat 267, 2060 Antwerp, Belgium

10 University Hospital Ghent, Department of Plastic Surgery, Burn Center, De Pintelaan 185, 9000 Ghent, Belgium
} 